\title{
Post-Thoracotomy Pain Syndrome
}

\author{
Anand Alister Joseph R., Anand Puttappa and Donal Harney \\ Mercy University Hospital, Cork, \\ Ireland
}

\section{Introduction}

Trauma and surgery have been well recognised as risk factors for developing chronic pain. The first published article on chronic post-surgical pain (CPSP) was in 1998 by Crombie and colleagues. Since then this concept has gained increasing popularity, evidenced by the dramatic increase in number of research publications focussing on post surgical pain states 1,5 . Despite this awareness, post surgical pain still remains poorly recognised and is under estimated as a cause for pain related morbidity. Post thoracotomy pain syndrome is one of such post surgical pain syndrome which remains a challenge to the treating physician both in terms morbidity for the individual and the incurring health costs on the society $2,3,5$.

Thoracotomy incisions are considered amongst the most painful incisions as it involves a significant amount of trauma and distraction forces on multiple muscle layers, fascia, neurovascular bundles, bone and joints and parietal pleura all of these being pain sensitive structures. This may also involve rib resection if surgically required ${ }^{4,6}$. A chronic pain state, which occurs after such surgical intervention, is called chronic post thoracotomy pain syndrome (PTPS). The International Association for the Study of Pain has defined post thoracotomy pain syndrome as 'Pain that recurs or persists along a thoracotomy incision atleast two months after the surgical procedure' 7 .

\section{Epidemiology}

There are major discrepancies in the reported prevalence of PTPS. This may in part be explained by the differences in study methodology which include but are not limited to the definition of PTPS, patient characteristics and the duration of follow up. PTPS ranges from $5-80 \%$ of thoracotomies and 5-33\% for video-assisted thoracoscopic surgeries (VATS) ${ }^{8-18}$. In a recent survey following patients after thoracotomies for lung cancer the incidence of PTPS was $33 \%$ for thoracotomies and $25 \%$ for VATS procedures. Clinically relevant pain was present in $11-18 \%$ and severe pain in $4-12 \%$, which depended on the level of physical activity. More than half of these patients reported pain from other parts. There is no clear evidence to suggest sex predominance but it was observed that women tended to report higher levels of pain with concomitant use of simple analgesics. And younger patients reported more pain as compared to the elderly ${ }^{19}$. There is little consensus regarding the impact that the type of surgery has on the clinical outcome in terms of PTPS. Some studies 
showing there being no convincing difference and others claiming that video-assisted thoracoscopic procedures to be superior ${ }^{8,20-23}$.

\section{Pathophysiology}

The etiopathogenesis of post-surgical pain syndromes is multifactorial and is yet to be fully elucidated. There still remains a large gap in our knowledge pertaining to the exact mechanisms involved and is a subject of constant debate with new evolving concepts. Postthoracotomy pain is by and large one of the classical post-surgical pain syndrome.

\subsection{Neurogenic mechanisms - neuroplasticity}

Neuroplasticity is a relatively new term and as the name denotes it refers to the inherent ability of the central nervous system to adapt, modify and transform itself both structurally and functionally. The central nervous system was once thought to be hard wired but now is viewed as a dynamic processing unit which responds to various stimuli.

Thoracotomies as previously mentioned involves trauma to various structures, most importantly the intercostal nerves. Injury to the intercostal nerves may occur directly as a result pressure on the nerves by surgical retractors or when surgical resection of the rib is performed or indirectly where the entire nerve is subjected to traction forces by the retractors resulting in ischaemia. The other possibilities being impingement from displaced rib fractures and nerve entrapment in scar tissue. The cycle of events which occur in chronic pain patients after nerve injury may be best explained as a maladaptive response where the nervous systems both the peripheral and central nervous systems are altered, becoming dysfunctional and resulting in a neuropathic pain state

\subsubsection{Peripheral sensitisation}

Nerve damage leads to an inflammatory response with the outpour of inflammatory mediators as the nerve undergoes degeneration. These mediators which include tumour necrosis factor, prostaglandins, histamine, potassium ions, bradykinin and other products of arachidonic acid degradation which are pro-nociceptive results in peripheral sensitisation. This results in a reduction of required magnitude of stimuli to trigger an action potential and thereafter the transmission of pain signals. This is manifested as primary and secondary hyperalgesia which are exaggerated responses in pain perception for the given noxious stimuli and also allodynia which is increased pain sensitivity to non-noxious stimuli. Primary hyperalgesia is an exaggerated response to stimuli at the damaged site and secondary hyperalgesia is that which is perceived in the surrounding undamaged tissue. While primary hyperalgesia is mainly a peripheral neural phenomenon, secondary hyperalgesia is thought to be a mediated within the central nervous system which is referred as central sensitisation.

\subsubsection{Central sensitisation}

Peripheral sensitisation results in increased activity in the nociceptors and their primary afferent neurons. Persistent exposure of the cell bodies of these neurons in the dorsal horn to noxious stimuli results in a hyper-excitable state called central sensitisation. The dorsal horn of the spinal cord plays a vital role in impulse modulation and transmission; its acts 
as a gateway between the peripheral nociceptors and the higher centres where pain in perceived. The dorsal horn functions as a gate where pain signals are either dampened or amplified and transmitted to the higher centres. In this dysfunctional state of hyperexcitability in the spinal cord, signal transmission is augmented at the spinal level along with influence from descending pathways resulting in sensitisation. Central sensitisation is therefore described as a pain amplification process of the central pain-processing unit where there is facilitation in pain transmission and widening of receptor field to stimuli. It is also speculated that cortical remapping occurs in persistent pain with the developments of new neural networks and unfolding of dormant synapses as part of the neuromatrix model.

While intercostal nerve injury is assumed to be the most important cause of PTPS, there is conflicting evidence in the literature. There is evidence to support the fact that intercostal nerve damage does occurs during surgery and that surgical factors may affect outcome. The pattern and degree of nerve damage has also being studied by neurophysiological studies of the intercostal nerve during and following surgery. Patients who have significant intercostal nerve damage like those with rib resection and fractures developed neuropathic pain. And those with neuropathic pain features develop significant chronic pain which may be disabling. Despite these facts to support this mechanism of pain, intercostal nerve damage nerve alone cannot be incriminated as the sole cause for chronic pain after thoracic surgery.

\subsection{Myofascial pain}

It is well recognised that patients with PTPS may have associated shoulder dysfunction. Soft tissue trauma, which includes muscle, fascia and connective tissue, may result in Myofascial pain syndrome.

\subsection{Local factors}

Tumour recurrence, infection, costochondritis, costochondrol disruption, costovertebral disruption, pleurisy and healing rib fractures may all contribute to ongoing pain after thoracotomy.

\begin{tabular}{|ll}
\hline 1. & Intercostal nerve injury - neuroma \\
2. & Tumour recurrence \\
3. & Myofascial pain syndrome \\
4. & Frozen shoulder \\
5. & Healing fracture ribs \\
6. & Costochondritis \\
7. & Costochondral disruption \\
8. & Costovertebral disruption \\
9. & Infection \\
10. & Pleuritis \\
11. & Psychological distress \\
\hline
\end{tabular}

Table 1. Cause of chronic post thoracotomy pain syndrome 


\section{Clinical presentation}

According to the nomenclature suggested by the IASP, any pain along the thoracotomy incision site, which is persistent beyond 2 months, is PTPS.7 In general, PTPS is largely neuropathic in nature with charctersitic features of neuropathic pain. A thorough assessment is required as with most pain syndromes is to differentaite between neuropathic, visceral and nociceptive pain; all of which aids in the management. In cancer patients, the appearnce of new pain or worsening of pain which was fairly under control may warrant further investigation to rule out disease progression.

\subsection{Neuropathic pain}

Neuropathic pain is present in majority of these patients and is manifested by an array of symptoms which include allodynia, hyperalgesia, dysaesthesia or parasthesia. Patients describe the pain as a sharp, shooting or stabbing pain along the scar line. They may also report pain along the dermatomal distribution of the affected intercostal nerves as a constant dysesthetic burning type pain. Table 3 .

\begin{tabular}{|l|l|}
\hline Allodynia & Pain due to a stimulus that does not normally provoke pain. \\
\hline Hyperalgesia & Increased pain from a stimulus that normally provokes pain \\
\hline Hyperesthesia & Increased sensitivity to stimulation, excluding the special senses. \\
\hline Hypoesthesia & Diminished pain in response to a normally painful stimulus \\
\hline Dysesthesia & An unpleasant abnormal sensation, whether spontaneous or evoked \\
\hline Paresthesia & An abnormal sensation, whether spontaneous or evoked \\
\hline
\end{tabular}

Table 2. Definitions of common neuropathic pain terms

\subsection{Myofascial pain}

Around one third of patients do not report features of neuropathic pain and myofacial pain, with local tenderness and shoulder dysfunction may predominant the clinical picture. Shoulder dysfunction is common and may be due to the division of the serratus anterior and latissimus dorsi muscle. This results in a viscious cycle of pain, lack of movements, muscle deconditioning and frozen shoulder.

\subsection{Visceral pain}

Visceral pain is usually as vague, constant, dull aching type of pain. The concept of visceral pain in gaining popularity and may account for those patients who do not present as neuropathic pain post thoracic surgery. Steegers et al 2008 found that this is more common with more extensive surgery and pleurectomy suggesting a visceral component to the PTPS.57

\section{Perioperative risk factors and preventive strategies}

Intercostal nerve damage is an important identifiable cause but not the sole pathogenic mechanism for chronic post thoracotomy pain. Researchers have attempted to identify risk factors associated with PTPS and investigate strategies which may reduce the incidence of PTPS. This has led to a number of publications on this topic but most fail to provide definitive evidence mainly due to inconsistencies in study design. The following table enumerates the various possible perioperative factors which may influence the occurrence of PTPS. 


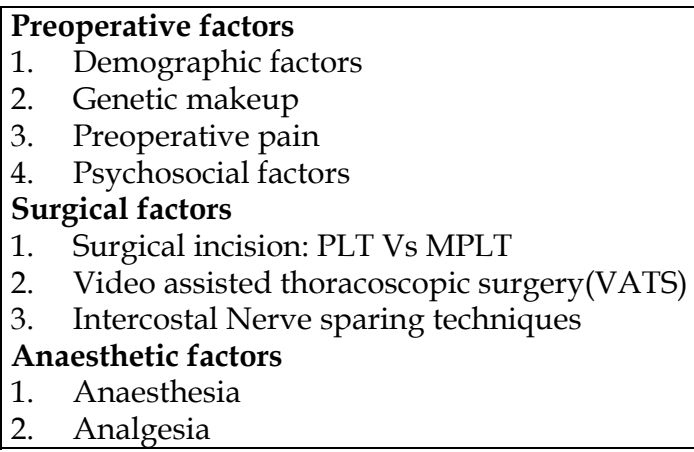

Table 3. Perioperative risk factors and preventive strategies

\subsection{Preoperative factors}

Preoperative preparation and optimisation is an important part in the care of the surgical patient and can have major influence on patient outcomes. Post thoracotomy pain syndrome is one such entity which may be indirectly influenced by preoperative optimisation. It has been shown that poorly controlled acute pain can progress to chronic pain states. Therefore it could be stated that patients who are appropriately optimised prior to surgery would do better after surgery in terms of being able to engage in the rehabilitative process and recover more rapidly thereby reducing the incidence of PTPS. The other important fact in the preoperative period is to appreciate post thoracotomy pain syndrome as one of the most common complications after thoracic surgery and being proactive could reduce its incidence Recognising this fact is vital in the management of these patients as appropriate identification of those at risk and developing management strategies may improve outcomes in terms of pain morbidity.

\subsubsection{Demographic factors}

Post surgical pain syndromes after mastectomies have been noted to occur less frequently with increasing age. But, factors such as type of tumour, their presentation and response to treatment need to be considered as these vary with age and may influence the incidence. Post herniorrhaphy pain also tends to decrease with increasing age. $24,25,27,28$ There is evidence to suggest a gender difference where women may be at a higher risk of developing post surgical pain. 19,28 Currently there is no definitive evidence to suggest that post thoracotomy pain has age or gender preponderance.

\subsubsection{Genetics}

In clinical practice we observe that there is significant inter-individual variability in the pattern in patient's presentation, progression and response to therapy. It is extremely difficult to predict the response of an individual to a given insult, there may be a role in the underlying genetic makeup of the individual which might explain why some patents are more prone to post surgical pain. The attempt to identify such genes which play a role in pain processing has shown some association with gene polymorphism of catechol-0methyltransferase (COMT), genetic variants to determine voltage-gated sodium channels and GTP cyclohydrolase and tetrahydrobiopterin-related genes. ${ }^{29,30,31}$ Laboratory studies 
show an association between genetic factors and the development of neuropathic pain after nerve injury. ${ }^{31}$ This may suggest that post thoracotomy pain in which nerve damage is a major pathogenic mechanism may be influenced by genetic factors.

\subsubsection{Psychological factors}

The biopsychosocial approach to pain is a broad multidimensional concept, which incorporates the traditional biomedical model and the psychodynamic model. In chronic pain states the impact of psychological factors (cognition, affect and behaviour) and social factors (social status, employment, litigation) may play an important role in exacerbation and maintaining pain. This impacts the outcome when assessed in terms of quality of life after surgery. 33 A systematic review on premorbid psychosocial status of depression, stress and psychological vulnerability showed a positive correlation between them and the development of chronic post surgical pain. Patients with higher level of depression and stress are at higher risk for development of chronic pain as is those who are psychologically vulnerable. ${ }^{34}$ Pain in the perioperative period as a risk factor for the development of emotional numbing as part of a post traumatic stress disorder was found to be significant predictor of pain disability at 6 and 12 months after lateral thoracotomy. Suggesting that de coupling of pain intensity and disability occurs while emotional numbing takes a more important role in pain disability. ${ }^{35}$ The correlation between psychosocial factors and the development of chronic pain after surgery is complex and remains challenge to investigate partly due to the inadequacies in measuring these factors.

\subsubsection{Preoperative pain}

Pre-existing pain and the use of pain medications has shown to correlate well with chronic post operative pain syndromes after hernia, limb amputation and breast surgery. ${ }^{25,36-38}$. Keller et al found a positive correlation with patients on pain medications in the preoperative period with those on pain medications having an incidence as high as 52\% compared to $5.5 \%$ for those not on pain medications. ${ }^{39}$ Most studies on the association between preoperative pain and chronic post thoracotomy pain syndrome have revealed inconsistent results as most studies exclude patients with pre-existing pain morbidity and pain medications.

\subsection{Surgical factors}

Surgery in general is now well recognised as a risk factor for chronic pain. Patients undergoing thoracic surgery have a high incidence of chronic pain, and as we have already seen that injury to the intercostal nerve has a major role in the pathogenesis of chronic post thoracotomy pain. Various surgical approaches and procedures to minimise nerve injury have been attempted over the years. These techniques will be discussed in the following section.

\subsubsection{Thoracotomy: Posterolateral approach Vs muscle sparing surgery}

Access to the thorax is either through a median sternotomy, anterior or anterolateral, lateral or posterior lateral, axillary and transverse sternothoracotomy incision. Among these the lateral and posterolateral approach (PLT) is considered to be the gold standard. The primary advantage of this approach is that it facilitates good access to intrapleural structures which include the lungs, oesophagus, chest wall and mediastinum. The main drawback is that of its invasiveness. This approach may involve rib transection or resection to optimise surgical exposure. But it is also the most painful of incisions because of its invasiveness which 
involves incision of the serratus anterior, latissimus dorsi and trapezius muscles. This results in the development of shoulder girdle dysfunction and pain which is a common occurrence in PTPS.40

In an attempt to reduce muscle trauma, a modification of the classic PLT approach called the muscle sparing posterolateral (MPLT) approach is increasingly being used. This approach does not involve the division of the latissimus dorsi muscle and the size of the incisions is smaller but provides optimal exposure for most pulmonary operations. The advantages of this approach is mainly due to the decreased muscle trauma and incision size, which results in decreased operative time, post operative pain, hospital stay and improved shoulder girdle function and cosmesis. The drawbacks being suboptimal exposure for some procedures especially where adhesions are present, a higher level of expertise is required and there is a higher incidence of seroma formation. ${ }^{41,42}$

Mario Nosotti et al 2010 published a prospectively conducted randomised controlled trial comparing the two techniques in patients undergoing pulmonary lobectomy. This was done with the primary endpoints of pain, analgesic consumption and post thoracotomy syndrome. The incision type influenced the analgesic consumption, hospital stay and shoulder strength positively in those who had a MPLT but the three year PTPS was not affected. ${ }^{43}$ The association between the incision type and the subsequent development of PTPS has not been established and there is a lack of well designed prospective studies focussing on this issue.

\subsubsection{Video-Assisted Thoracoscopic Surgery (VATS)}

Video assisted thoracoscopic surgery is adopted from the well established and increasingly popular laparoscopic surgical technique in an attempt to avoid large surgical incision and thereby conceived as a minimally invasive technique. But in the case of chronic pain morbidity after VATS there is no current evidence to suggest the superiority of this technique with conflicting reports. Conceptually, the avoidance of large thoracotomy incisions would result in lesser trauma to the neurovascular bundle and thus reduced incidence of PTPS. Unfortunately this is not translated clinically and intercostal nerve injury does occur probably by compressive and distractive forces by thoracoscopic manipulation like excessive torquing of the thoracosope which may cause rib fractures and intercostal nerve injury. And in inexperienced hands and patients with adhesions operating time may be prolonged. Moreover multiple ports may be required and extraction of resected segments may require a small thoracotomy incision and small incisions requiring more force to retract the ribs increasing the possibility of nerve damage. It is accepted that VATS surgery is favourable in short terms outcomes of immediate post operative pain scores, opioid consumption and hospital stay but not different in the long term outcome of PTPS.4,44,45

\subsubsection{Intercostal nerve sparing techniques}

Techniques to reduce the injury caused to the intercostal nerves have shown positive results with a trend towards reduced incidence of chronic PTPS. Retraction on the ribs and the use of pericostal sutures can cause significant injury to the intercostal nerves. This may be overcome partially by dissecting out an intercostal flap or by using intracostal sutures as opposed to pericostal sutures. Pericostal sutures which are commonly used suture technique are placed on the top of the $5^{\text {th }}$ rib and $7^{\text {th }}$ rib whereas intracostal sutures involve the drilling of small hole in the underlying rib and closing the thoracotomy wound with sutures through these holes. 
Cerfolio et al 2003, in a prospective radomised controlled trial in 280 patients comparing the two suture techniques found that there was reduced pain in the intracostal at 3 months and that these patients reported lesser neuropathic descriptors of burning and shooting type pain. ${ }^{46}$

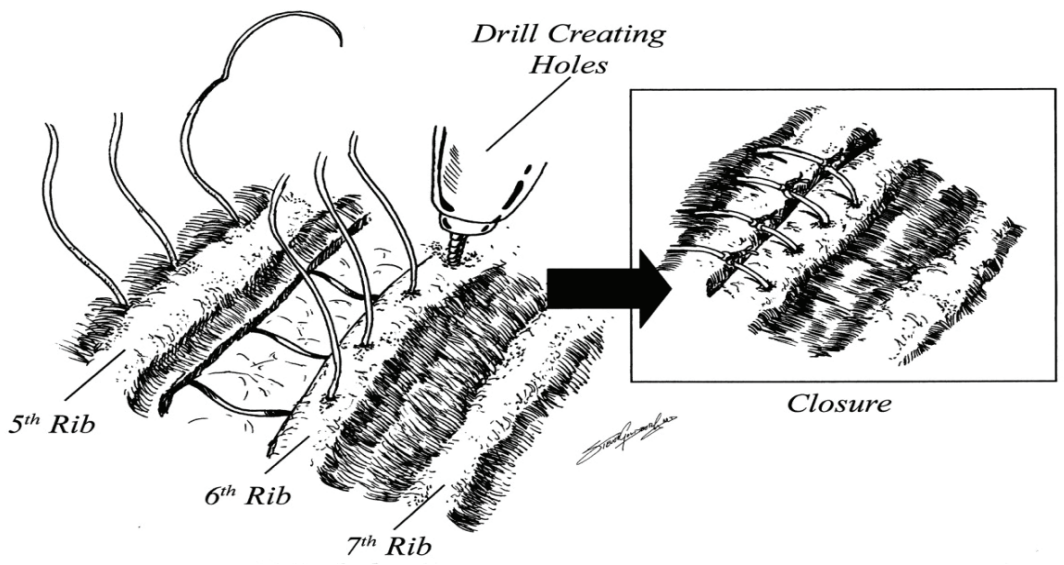

Fig. 1. Intracostal sutures: holes are created in the adjacent ribs and closure is done intracostally excluding the neurovascular bundle in the closure.

Intercostal flap have been long used to cover bronchial stumps but Cerfolio et al investigated the use of this technique for reducing post thoracotomy pain. In the two prospective randomised controlled studies performed by this group one involving a free intercostal muscle (ICM) flap transected anteriorly and the other study which maintained a non-divided ICM flap. Both studies showed a decrease in post thoracotomy pain at 3 months. ${ }^{47,} 48$

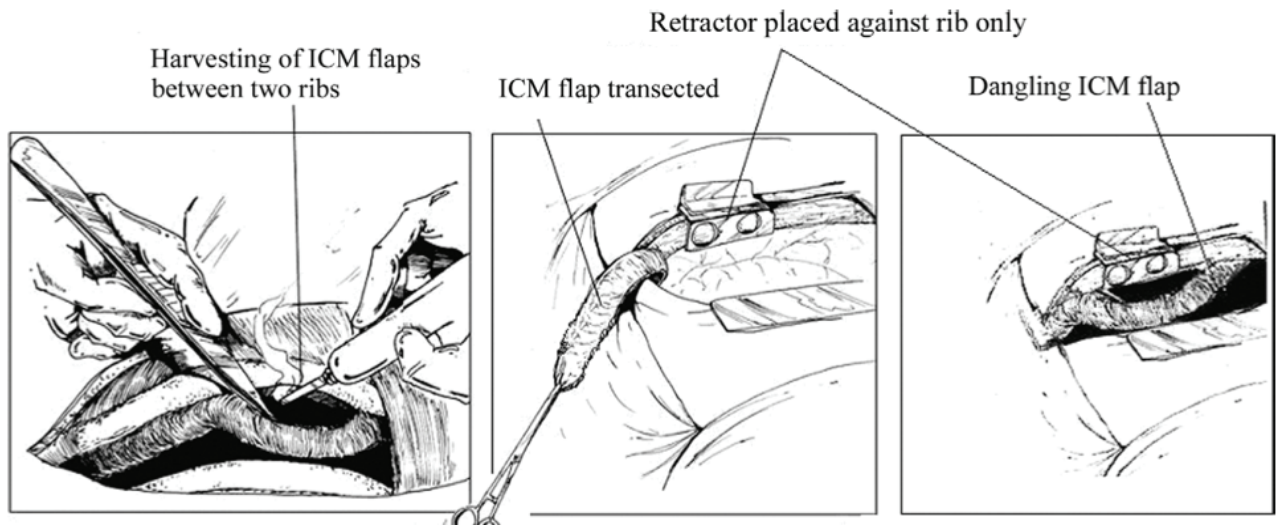

Fig. 2. Intercostal muscle flap (ICM). ICM flap techniques are used to exclude the neurovascular bundle from retraction. Two techniques are shown, the common first step being harvesting of the intercostal muscle flap after which it may be either transacted and excluded or allowed to dangle freely avoiding retraction. 
The use of specialised retractors have been studied in animal models which can monitor tissue distractive force and thereby act as a feedback mechanism such that the least amount of force is used in obtaining optimal exposure. 49

\subsection{Anaesthesia and analgesic factors 5.3.1 Anaesthesia}

The impact which an anaesthetic technique has on the long term effects of PTPS is unclear. Most studies focus on the analgesic technique used, primarily regional anaesthetic techniques. Remifentanil, which is a pure $\mu$ opioid receptor agonist, is increasingly being used in anaesthesia; primarily for its rapid onset and offset of action, which is non-reliant on organ metabolism. In a recent publication, Salengros et al 201050 conducted a prospective randomised controlled trial comparing low dose remifentanil and intraoperative thoracic epidural analgesia with high dose remifentanil and post operative epidural analgesia. The patients in the high dose remifentanil group had larger areas of allodynia in the immediate $72 \mathrm{hrs}$ postoperatively and also had a higher incidence of chronic PTPS which was mainly neuropathic in character. This could be explained by either the timing of the epidural or the use of high dose remifentanil. The timing of epidural analgesia has been studied and there is no consensus of its effect on the long term outcome of PTPS. A recent meta-analysis ${ }^{51}$ failed to demonstrate that timing of epidural analgesia had any influence on long term outcome. The other possibility is the development of acute opioid induced hyperalgesia $(\mathrm{OIH})$ with the use of remifentanil which is now an established phenomenon. There is good evidence to support OIH from both laboratory and clinical research. This brings to light, as the author concludes stating that even widely accepted anaesthetic practices may have a large impact on long-term outcomes and it is important that we recognise these facts.

\subsubsection{Analgesia}

Various regional anaesthetic techniques have been used as part of a balanced anaesthetic technique to provide adequate intraoperative and postoperative analgesia. The techniques used include intercostal nerve blocks, interpleural block, cryoanalgesia, paravertebral block and thoracic epidural analgesia. It is considered that adequate analgesia especially during surgery when there is maximal nociceptive input is an important cause for sensitisation both peripheral and central sensitisation, which results is chronic post surgical pain. Establishing a regional anaesthetic technique which abolishes this flow of impulses could reduce sensitisation and thus result in better long term outcomes.52,53 Practically it remains a challenge to achieve as it is difficult adequately monitor and completely abolish nociceptive input. Moreover the neurohumoral factors which are triggered by the stress of surgery and anaesthesia resulting in the outpour of proinflammatory cytokines leading to hypersensitivity. This may partially explain the discrepancies in the published data on these techniques, where there are both positive and negative outcomes on each technique. Most investigations concentrate on short term endpoints like post operative pain intensity, analgesic requirements, hospital stay and immediate complications with very few analysing the long term occurrence of chronic PTPS. The published data on the use of these techniques are also flawed by 
methodological inadequacies and very little if any can be extrapolated in terms of chronic pain morbidity. ${ }^{52,}$ 44-56 But it appears that choosing an appropriate technique which can provide reliable analgesia could help in the improving outcomes.

\section{Conclusion}

After the above discussion regarding the various factors which influence the occurrence of post thoracotomy pain syndrome, the etiopathogenic mechanisms involved and the possible strategies to improve outcome; it is evident that the management of this clinical condition is challenging and further research is required. There is ongoing interest in this field in thoracic surgery and as previously discussed the broader category of post surgical pain syndromes in which this belongs is increasingly being recognised. Education and creation of a general awareness both in the medical profession and the general public would help up manage this problem more successfully with probably better outcomes.

\section{References}

[1] Crombie IK, Davies HT, Macrae WA. Cut and thrust: antecedent surgery and trauma among patients attending a chronic pain clinic. Pain 1998; 76:167-71.

[2] Blyth FM, March LM, Cousins MJ. Chronic pain-related disability and use of analgesia and health services in a Sydney community. Med J Aust 2003;179:84-7

[3] Schnabel A, Pogatzki-Zahn E. [Predictors of chronic pain following surgery. What do we know?]. Schmerz 2010;24:517-31; quiz 532-3.

[4] Stephen R. Hazelrigg, MDa, ${ }^{*}$, Ibrahim B. Cetindag, MDa, James Fullerton, Mdb, Acute and chronic pain syndromes after thoracic surgery,Surg Clin N Am 82 (2002) 849865

[5] Stephan A. Schug, Esther M. Pogatzki-Zahn. Chronic Pain after Surgery or Injury. IASP Clinical Updates Vol. XIX, Issue 1 January 2011

[6] Peter Gerner,Post-thoracotomy Pain Management Problems,Anesthesiol Clin. 2008 June ; 26(2): 355-vii

[7] Merskey H, Bogduk H. Classification of chronic pain. In: Merskey H, Bogduk H, editors. Descriptions of chronic pain syndromes and definitions of pain terms. Second Edition. Seattle: IASP Press; 1994. pp. 143-144

[8] Landreneau RJ. Prevalence of chronic pain after pulmonary resection by thoracotomy or video-assisted thoracic surgery. J Thorac Cardiovasc Surg 1994; 107(4): 1079— 86

[9] Passlick B, Born C, Sienel W, Thetter O. Incidence of chronic pain after minimalinvasive surgery for spontaneous pneumothorax. Eur J Cardio-thorac Surg 2001; 19:355-9.

[10] Lang-Lazdunski L, Chapius O, Bonnet PM, Pons F, Jancovici R. Videothor- acoscopic bleb excision and pleural abrasion for the treatment of primary spontaneous pneumothorax: long-term results. Ann Thorac Surg 2003; 75:960-5.

[11] Landreneau RJ, Pigula F, Luketich JD, Keenan RJ, Bartley S, Fetterman LS, Bowers CM, Weyant RJ, Ferson PF. Acute and chronic morbidity differences between muscle- 
sparing and standard lateral thoracotomies. J Thorac Cardiovasc Surg 1996; 112(5): $1346-50$.

[12] Passlick B, Born C, Sienel W, Thetter O. Incidence of chronic pain after minimalinvasive surgery for spontaneous pneumothorax. Eur J Cardio-thorac Surg 2001; 19:355-9.

[13] Stammberger U, Steinacher C, Hillinger S, Schmid RA, Kinsbergen T, Weder W. Early and long-term complaints following video-assisted thor- acoscopic surgery: evaluation in 173 patients. Eur J Cardiothoracic Surg 2000; 18:7-11.

[14] Hutter J, Miller K, Moritz E. Chronic sequels after thoracoscopic procedures for benign diseases. Eur J Cardiothoracic Surg 2000;17:687-90.

[15] Perttunen K, Tasmuth T, Kalso E. Chronic pain after thoracic surgery: a follow-up study. Acta Anaesthesiol Scand 1999; 43:563-7.

[16] Dajczman E, Gordon A, Kreisman H, Wolkove N. Long-term post-thoracotomy pain. Chest 1991; 99:270-4.

[17] Katz J, Jackson M, Kavanagh B, Sandler AN. Acute pain after thoracic surgery predicts long-term post-thoracotomy pain. Clin J Pain 1996; 12 (1): 50-5.

[18] Keller SM, Carp NZ, Levy MN, Rosen SM. Chronic post thoracotomy pain, J Cardiovasc Surg 1994; 35(Suppl. 1-6): 161-4

[19] Ochroch EA, Gottschalk A, Troxel AB, Farrar JT,Women suffer more short and longterm pain than men after major thoracotomy,Clin J Pain. 2006 Jun;22(5):491-8

[20] Furrer M, Rechsteiner R, Eigenmann V, Signer C, Althaus U, Ris HB. Thoracotomy and thoracoscopy: postoperative pulmonary function, pain and chest wall complaints. Eur J Cardiothoracic Surg 1997 July; 12(1): 82-7

[21] Maguire MF, Ravenscroft A, Beggs D, Duffy JP. A questionnaire study investigating the prevalence of the neuropathic component of chronic pain after thoracic surgery. Eur J Cardiothorac Surg 2006 May; 29(5): 800-5.

[22] Forster R, Storck M, Schafer JR, Honig E, Lang G, Liewald F. Thoracoscopy versus thoracotomy: a prospective comparison of trauma and quality of life. Langenbecks Arch Surg 2002 April; 387(1): 32-6

[23] K. Wildgaard, J.Ravn, L.Nikolajsen, E.Jackobsen, T. S.Jensen and H. Kehlet, Consequences of persistent pain after lung cancer surgery: a nationwide questionnaire study, Acta Anaesthesiol Scand 2011; 55: 60-68

[24] Aasvang E, Kehlet H. Chronic postoperative pain: the case of inguinal herniorrhaphy. Br J Anaesth 2005; 95: 69-76.

[25] Poobalan AS, Bruce J, Smith WC, King PM, Krukowski ZH, Chambers WA. A review of chronic pain after inguinal herniorrhaphy. Clin J Pain 2003; 19: 48-54

[26] Katz J, Poleshuck EL, Andrus CL, et al. Risk factors for acute pain and its persistence following breast cancer surgery. Pain 2005; 119:16-25.

[27] Kalkman CJ, Visser K, Moen J, Bonsel GJ, Grobbee DE, Moons KG. Preoperative prediction of severe postoperative pain. Pain 2003; 105: 415-23

[28] Kehlet H, Jensen TS, Woolf CJ. Persistent postsurgical pain: risk factors and prevention. Lancet 2006;367(9522):1618-25 
[29] Pan PH, Coghill R, Houle TT, Seid MH, Lindel WM, Parker RL, Washburn SA, Harris L, Eisenach JC. Multifactorial preoperative predictors for postcesarean section pain and analgesic requirement. Anesthesiology 2006;104(3):417-25

[30] Diatchenko L, Nackley AG, Tchivileva IE, Shabalina SA, Maixner W. Genetic architecture of human pain perception. Trends Genet 2007;23(12):605-13

[31] Max MB, Stewart WF. The molecular epidemiology of pain: a new discipline for drug discovery. Nat Rev Drug Discov 2008;7(8):647-58

[32] Seltzer Z, Wu T, Max MB, Diehl SR. Mapping a gene for neuropathic pain-related behaviour following peripheral neurectomy in the mouse. Pain 2001; 93: 101-6

[33] Thomas Hadjistavropoulos,Kenneth D. Craig, PainPSYCHOLOGICAL PERSPECTIVES, ISBN 0-8058-4299-3

[34] Anke Hinrichs-Rocker, Kerstin Schulz, Imke Järvinen, Rolf Lefering,Christian Simanski, Edmund A.M. Neugebauer, Psychosocial predictors and correlates for chronic post-surgical pain (CPSP) - A systematic review, European Journal of Pain 13 (2009) 719-730

[35] Joel Katz, Gordon J.G. Asmundson, Karen McRae, Eileen Halket, , Emotional numbing and pain intensity predict the development of pain disability up to one year after lateral thoracotomy, European Journal of Pain 13 (2009) 870-878

[36] Liem MS, van Duyn EB, van der Graaf Y, van Vroonhoven TJ.Recurrences after conventional anterior and laparoscopic inguinal hernia repair: a randomized comparison. Ann Surg 2003;237: 136-41 Wright D, Paterson C, Scott N, Hair A, O'Dwyer PJ. Five-year follow-up of patients undergoing laparoscopic or open groin hernia repair: a randomized controlled trial. Ann Surg 2002;235: 3337

[37] Nikolajsen L, Ilkjaer S, Kroner K, Christensen JH, Jensen TS. The influence of preamputation pain on postamputation stump and phantom pain. Pain 1997; 72: $393-405$

[38] Kroner K, Knudsen UB, Lundby L, Hvid H. Long term phantom breast syndrome after mastectomy. Clin J Pain 1992; 8: 346-50

[39] Keller SM, Carp NZ, Levy MN, Rosen SM. Chronic post thoracotomy pain. J Cardiovasc Surg 1994; 35: 161-4

[40] Robert J Baker, Josef E Fischer, Mastery of Surgery, ISBN: 0-7817-2328-0

[41] Landreneau RJ, Pigula F, Luketich JD, Keenan RJ, Bartley S, Fetterman LS, Bowers CM, Weyant RJ, Ferson PF. Acute and chronic morbidity differences between musclesparing and standard lateral thoracotomies. J Thorac Cardiovasc Surg 1996;112(5):1346-50

[42] Kalso E, Perttunen K, Kaasinen S. Pain after thoracic surgery. Acta Anaesthesiol Scand 1992;36:96-100 Khan IH, McManus KG, McCraith A, McGuigan JA. Muscle sparing thoracotomy: a biomechanical analysis confirms preservation of muscle strength but no improvement in wound discomfort. Eur J Cardiothorac Surg 2000;18(6):656-61.

[43] Mario Nosottia, Alessandro Baisib, Paolo Mendognia, ${ }^{*}$, Alessandro Palleschia, Davide Tosia, Lorenzo Rossoa, Muscle sparing versus posterolateral thoracotomy for 
pulmonary lobectomy: randomised controlled trial, Interactive CardioVascular and Thoracic Surgery 11 (2010) 415-419

[44] Iwasaki A, Kawahara K. The role of video-assisted thoracic surgery for the treatment of lung cancer: lung lobectomy by thoracoscopy versus the standard thoracotomy approach. Int Surg 2000;85(1):6-12

[45] Kirby TJ, Mack MJ, Landreneau RJ, Rice TW. Lobectomy-video-assisted thoracic surgery versus muscle-sparing thoracotomy. A randomized trial. J Thorac Cardiovasc Surg 1995;109(5):997-1001

[46] Cerfolio RJ, Price TN, Bryant AS, Sale BC, Bartolucci AA. Intracostal sutures decrease the pain of thoracotomy. Ann Thorac Surg 2003;76(2):407-11

[47] Cerfolio RJ, Bryant AS, Patel B, Bartolucci AA. Intercostal muscle flap reduces the pain of thoracotomy: a prospective randomized trial. J Thorac Cardiovasc Surg 2005;130(4):987-93.

[48] Cerfolio RJ, Bryant AS, Maniscalco LM. A nondivided intercostal muscle flap further reduces pain of thoracotomy: a prospective randomized trial. Ann Thorac Surg 2008;85(6):1901-6

[49] Gil Bolotin, Gregory D Buckner, Nicholas J Jardine, Aaron J Kiefer, Nigel B Campbell, BVetMed, Masha Kocherginsky,Jai Raman and Valluvan Jeevanandam, A novel instrumented retractor to monitor tissue-disruptive forces during lateral thoracotomy The Journal of Thoracic and Cardiovascular Surgery ,Volume 133, Number 4949

[50] Jean-Corentin Salengros,Isabelle Huybrechts, Anne Ducart ,David Faraoni,Corinne Marsal, Luc Barvais,Matteo Cappello and Edgard Engelman,Different Anesthetic Techniques Associated with Different Incidences of Chronic Post-thoracotomy Pain: Low-Dose Remifentanil Plus Presurgical Epidural Analgesia is Preferable to High-Dose Remifentanil with Postsurgical Epidural Analgesia, Journal of Cardiothoracic and Vascular Anesthesia, Vol 24, No 4 (August), 2010: pp 608616

[51] Bong CL, Samuel M, Ng JM, et al: Effects of preemptive epidural analgesia on postthoracotomy pain. J Cardiothorac Vasc Anesth 19:786-793, 2005

[52] Kim Wildgaard , Jesper Ravn , Henrik Kehlet,Chronic post-thoracotomy pain: a critical review of pathogenic mechanisms and strategies for prevention, European Journal of Cardio-thoracic Surgery 36 (2009) 170-180

[53] Peter Gerner, Post-thoracotomy Pain Management Problems Anesthesiol Clin. 2008 June ; 26(2): 355-vii

[54] Kissin I. Preemptive analgesia. Anesthesiology 2000 October;93(4):1138-43. [PubMed: 11020772]

[55] Kissin I. Study design to demonstrate clinical value of preemptive analgesia: is the commonly used approach valid? Reg Anesth Pain Med 2002 May;27(3):242-4. [PubMed: 12016595]

[56] Samad TA, Moore KA, Sapirstein A, Billet S, Allchorne A, Poole S, Bonventre JV, Woolf CJ. Interleukin-1beta-mediated induction of Cox-2 in the CNS contributes to inflammatory pain hypersensitivity. Nature 2001 March 22;410(6827):471-5. [PubMed: 11260714] 
[57] Monique A. H. Steegers,Daphne M. Snik, Ad F. Verhagen,† Miep A. van der Drift and Oliver H. G. Wilder-Smith, Only Half of the Chronic Pain After Thoracic Surgery Shows a Neuropathic Component, The Journal of Pain, Vol 9, No 10 (October), 2008: pp 955-961 
TOpics w

THORACIC SURGERY

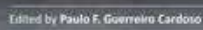

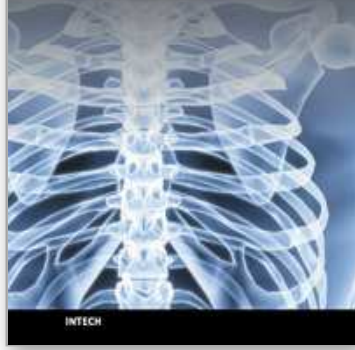

\section{Topics in Thoracic Surgery}

Edited by Prof. Paulo Cardoso

ISBN 978-953-51-0010-2

Hard cover, 486 pages

Publisher InTech

Published online 15, February, 2012

Published in print edition February, 2012

Thoracic Surgery congregates topics and articles from many renowned authors around the world covering several different topics. Unlike the usual textbooks, Thoracic Surgery is a conglomerate of different topics from Pre-operative Assessment, to Pulmonary Resection for Lung Cancer, chest wall procedures, lung cancer topics featuring aspects of VATS major pulmonary resections along with traditional topics such as Pancoast tumors and recurrence patterns of stage I lung disease, hyperhidrosis, bronchiectasis, lung transplantation and much more. This Open Access format is a novel method of sharing thoracic surgical information provided by authors worldwide and it is made accessible to everyone in an expedite way and with an excellent publishing quality.

\section{How to reference}

In order to correctly reference this scholarly work, feel free to copy and paste the following:

Anand Alister Joseph R., Anand Puttappa and Donal Harney (2012). Post-Thoracotomy Pain Syndrome, Topics in Thoracic Surgery, Prof. Paulo Cardoso (Ed.), ISBN: 978-953-51-0010-2, InTech, Available from: http://www.intechopen.com/books/topics-in-thoracic-surgery/post-thoracotomy-pain-syndrome-2

\section{INTECH}

open science | open minds

\section{InTech Europe}

University Campus STeP Ri

Slavka Krautzeka 83/A

51000 Rijeka, Croatia

Phone: +385 (51) 770447

Fax: +385 (51) 686166

www.intechopen.com

\section{InTech China}

Unit 405, Office Block, Hotel Equatorial Shanghai

No.65, Yan An Road (West), Shanghai, 200040, China

中国上海市延安西路65号上海国际贵都大饭店办公楼 405 单元

Phone: +86-21-62489820

Fax: $+86-21-62489821$ 
(C) 2012 The Author(s). Licensee IntechOpen. This is an open access article distributed under the terms of the Creative Commons Attribution 3.0 License, which permits unrestricted use, distribution, and reproduction in any medium, provided the original work is properly cited. 